\title{
O SANEAMENTO BÁSICO NO ENSINO EM ENFERMAGEM
}

\author{
Daisy Leslie Steagall Gomes *
}

\section{I - INTRODUÇÃO}

Cabe à enfermeira, entre suas diferentes atividades, colaborar com o saneamento, procurando dedicar sua atenção aos fatores do meio-ambiente que possam afetar a saúde.

Devido às funções que desempenham as enfermeiras, é necessário que elas tenham, em sua formação, conhecimentos que lhes possibilitem o trabalho no campo da saúde pública. Esses conhecimentos se estendem, entre outros, às ciências sociais, técnicas de comunicação e princípios de didática que são aplicáveis à enfermagem de saúde pública.

A disciplina saneamento, ministrada no Curso de Graduação em Enfermagem, oferece aos alunos oportunidade para adquirirem conhecimentos e desenvolverem hábitos e atitudes. Através do estudo do saneamento é evidenciada a importância: a) da água, do destino dos dejetos, águas servidas e lixo; da higiene da habitação, e dos alimentos; b) do controle dos artrópodes e roedores e da rela(.ĩo estreita entre estes fatores e o aparecimento de parasitoses e enfermidades transmissíveis.

Ademais, a importância do saneamento e sua relação com o aparecimento de doenças, coloca-o como meta prioritária em nossos programas de saúde, uma vez que há locais em nossas comunidades, que não possuem condições e recursos de saneamento. Isto tem levado ao agravo do problema de saúde naquelas populações, que são mais vułneráveis às doenças parasitárias e às enfermidades transmissiveis.

Dar aos alunos só conhecimento teórico do saneamento não é suficiente. Achamos que uma oportunidade deveria ser dada para

(*) Auxiliar de Ensino junto à disciplina de Enfermagem de Saúde Pública do Departamento de Enfermagem-Geral Especializada, da Escola de Enfermagem de Ribeirão Preto, U.S.P. 
que os estudantes nbservassem as ligações existentes entre o aparecimento de doenças e condições ambientais, bem como as oportunidades que a enfermeira de saúde pública tem para aplicar os seus conhecimentos a fim de educar e orientar os membros da comunidade para os problemas encontrados na população, que exigem melhoria das condições ambientais.

\section{II - OBJETIVOS}

Partindo dessa premissa, estabelecemos que, após o estudo de saneamento, os alunos deveriam ser capazes de:

1 - identificar os problemas encontrados e que estão relacionados com o saneamento básico;

2 - enumerar, por prioridade, as medidas que devem ser executadas na solução dos problemas do meio-ambiente;

3 - identificar as instituições da cidade, para as quais poderão ser encaminhadas as pessoas, para a solução de problemas ligados ao saneamento;

4 - especificar as doenças, cujo aparecimento está ligado às condições ambientais;

5 - resolver junto com a família, e de acordo com as possibilidades, medidas de melhoria das condições existentes;

6 - planejar atividades educativas, visando a promoção de saúde e prevenção de doenças, com a finalidade de levar as famílias e grupos da comunidade, por eles próprios, a se interessarem pelas medidas, visando melhoria do ambiente físico e da preservação da saúde;

7 - integrar conhecimentos de outras disciplinas ao saneamento na execução de trabalhos junto às famílias e à comunidade.

\section{III — PROGRAMA}

O ensino da disciplina de saneamento foi planejado e excutado para o segundo semestre letivo do Curso de Graduação em Enfermagem, da Escola de Enfermagem de Ribeirão Preto, USP, no ano de 1970, para uma classe de trinta e um alunos, com uma carga horária de 45 horas teóricas e 30 práticas (5 créditos).

\section{Conteúdo:}

1 - saneamento e suas ligações com enfermagem de saúde pública, estatística, parasitologia e sociologia; 
- água, águas residuárias, lixo, habitação, artrópodes e roedores e saneamento dos alimentos.

Desenvolvimento do Programa:

A - Tópico: "Saneamento e suas ligações com enfermagem de saúde pública, estatística, parasitologia e sociologia”, foi apresentado sob forma de painel, cujos participantes foram os professores de: parasitologia, sociologia e estatística, e de enfermagem de saúde pública e saneamento, cuja exposição seguiu a seguinte linha:

Parasitologia: O professor abordou as doenças parasitárias que são classificadas como as "mais importantes" e sua distribiução em nosso meio. Enfatizou a profilaxia de cada uma, acentuando o papel do saneamento e da educação sanitária na quebra do ciclo las parasitoses. Situou, no panorama médico, nossa atual posição de ainda estarmos "enfrentando os problemas de saúde ligados às doen(«s parasitárias”.

Sociologia: Foram apontados os fatores sócio-culturais ligados à alimentação, os tabus que criam resistência ao consumo de alguns alimentos, suas implicações na forma de comportamento das pessooas, bem como a força desses tabus no campo da saúde, e na forma de assimilação das "prescrições" que fazemos das normas alimentares para o bom equilíbrio da saúde.

Estatística: o professor evidenciou a importância do planejamento de um experimento para que os dados colhidos pudessem, tanto quanto possivel, exprimir a realidade dos fatos. Nesse sentido deu especial realce:

a) à necesidade de definir com precisão a população em estudo;

b) a processo de amostragem a ser utilizado e às vantagens de se utilizarem processos probabilísticos de amostragem;

c) ao cuidado na confecção do questionário (levantamento de dados relevantes) e padronização de seus aplicadores;

d) à fixação do grau de precisão desejada, quando possível;

e) às técnicas mais recomendadas para o levantamento, apuração e descrição dos dados;

f) ao sumário e análise dos dados e aos comentários e críticas dos resultados obtidos.

(*) Mais importante no sentido epidemiológico. 
Enfermagem de Saúde Pública e Saneamento: Foram definidos: saúde, enfermagem de saúde pública e saneamento.

Foi enfatizada a importância do saneamento para o enfermeiro pela contribuição que traz à redução e, às vezes, eliminação de doenças transmissíveis.

A professora mostrou que o papel do enfermeiro no saneamento tem o sentido de contribuir para promoção da saúde e prevenção de doenças, através de orientações, notificações de achados, informações prestadas, exposição dos meios e recursos de que pessoas e famílias dispõem, a fim de que estas, através de seus próprios esforços, obtenham as medidas desejadas. A contribuição da enfermeira é feita observando: o consumo de água, o preparo e seleção de alimentos, o destino dado às eliminações e ao lixo, as condições da habitação e do quintal e presença de artrópodes e roedores.

Apontou, igualmente, que o papel da enfermeira não é somente colocar a disposição da população os recursos de saneamento mas também ensiná-la e educá-la para o uso. Apontou situações em que a população dispõe de instalações sanitárias mas que não quer usá-las, e a necessidade de orientação para o uso desses benefícios, para a criação de hábitos higiênicos, principalmente entre as crianças.

B - Os assuntos abrangidos pelo item 2 foram apresentados sob forma de simpósio. A classe foi dividida em seis grupos, cada um recebeu um assunto e a bibliografia correspondente, com data e local de apresentação.

Como complementação, foi pedido que cada grupo visitasse instituições relacionadas com $o$ assunto estudado e apresentasse $o$ relatório da visita.

O preparo dos simpósios foi feito na sala-de-aula, cada grupo com seu coordenador e secretário, sob a supervisão da professora de saneamento.

Os assuntos apresentados em simpósios e as visitas realizadas foram os seguintes:

Água - Visita e entrevista no serviço de engenharia da prefeitura local. Visita aos poços de abastecimento da cidade.

Águas residuárias - Visita e entrevista ao departamento de águas e esgoto da prefeitura local para obtenção de informações sobre destino das águas residuárias na cidade.

Lixo - Visita a usina local de industrialização do lixo.

Habitação - Visita ao setor de engenharia da prefeitura local. 
Artrópodes e roedores - Visita ao Departamento de Parasitologia da Faculdade de Medicina de Ribeirão Preto e ao Serviço da Malária.

Saneamento dos Alimentos - Visita a Usina de Laticínio, ao Mercado Municipal e a uma indústria de bebida.

Excursão de todo o grupo ao Serviço Especial de Saúde de Araraquara para conhecer o Serviço de Enfermagem de Saúde Pública, a Divisão de Saneamento e a Estação de Tratamento de Água.

C - Além das visitas e excursões, os estudantes realizaram trabalho de campo.

Para estudo e elaboração do plano de trabalho de campo, foi feita uma reunião da classe com os professores de estatística, sociologia, parasitologia e enfermagem de saúde pública e saneamento, sob a coordenação deste último. Após estudo e discussão das propostas feitas, aceitou-se a que passaremos a expor, pelp - - qão de ter sido considerada a mais viável.

\section{Plano do Trabalho de Campo}

A - Selecionar dois grupos (Grupos A e B) distintos de população da cidade e conhecer de cada um:

1 - condições de habitação;

2 - abastecimento de água;

3 - destino dos dejetos;

4 - destino do lixo;

5 - existência de horta;

6 - criação de animais;

7 - fixação da família na localidade;

8 - composição familiar;

9 - religião;

10 - identificação de líderes;

11 - condições do quintal;

12 - providências da família em casos de doença.

B - Fazer exames de fezes de todos os elementos desses dois grupos selecionados, para constatar a presença de parasitas.

C - Estudar os dados dos grupos A e B e compará-los.

D - Tratar e encaminhar os indivíduos parasitados. 
E - Fazer orientação em saúde para os dois grupos, no sentido de esclarecê-los quanto às condições do saneamento, que podem ser melhoradas dentro de suas possibilidades.

\section{Material e Método}

Foram escolhidos dois bairros para o trabalho: um na zona residencial e outro na zona periférica.

A escolha dos bairros não foi aleatória, mas intencional.

Dentro dos bairros, foi selecionado um quarteirão e desse quarteirão, quatro (4) casas.

Bairro $A$ - Bairro periférico da cidade, situado num local onde há casas de difícil acesso, pela ausência de guias e ruas e pela invasão de vegetação que dificulta o acesso. As casas não obedecem a nenhum planejamento, constituídas de barracos, alguns de barro, outros de tijolo, outras de madeira e raras de alvenaria.

Há linhas de ônibus que chegam até uma via principal. Daí até alcançar o bairro o acesso tem que ser feito a pé, bicicleta, veículo com tração animal e carro, até próximo a algumas casas. Não possui rede de água, esgotos e luz elétrica. É considerado um dos bairros de condição sócio-econômico-educacional dos mais baixos. A ocupação das pessoas é na maioria, servente de pedreiros, pedreiros e trabalhadores de lavoura.

Bairro $B$ - Situado no limite de bairro residencial. Possui água encanada, rede de esgoto, luz elétrica e coleta diária de lixo. E todo calçado, com vias arborizadas. Possui algumas casas de comércio (armazéns, açougues, lojas e "boutiques") e está nas imediações de um hospital particular e outro hospital-escola. Sua população tem vários níveis de ocupação: comerciário, comerciante, professora, estudante, confeiteiro, dentista, operário etc.

0 acesso ao bairro é facilitado por avenidas e vias preferenciais que possuem linha de ônibus além dos carros de propriedade particular dos moradores. É considerado um bairro de alta condição sócio-econômico-cultural.

Foram escolhidas quatro (4) famílias de cada bairro para o trabalho, num total de oito (8). Esta limitação da escolha foi baseada nas restrições de tempo e material.

O trabalho seria desenvolvido através de visitas domiciliares na seguinte ordem:

Para os dois grupos (A e B) 
$1 .^{9}$ visita:

conhecimento da família, explicação da visita, do trabalho e dos exames a serem feitos; levantamento de dados (preenchimento do questionário);

- entrega de lata e espátula para colheita de fezes;

- orientação de como colher esse material e aviso do dia e hora que este seria recolhido;

responder às perguntas da família.

$2 .^{a}$ visita:

- recolhimento das latinhas com material;

-.. orientação sobre a relação de verminoses e o saneamento ambiental;

- encaminhamento do material ao Departamento de Parasitologia da Faculdade de Medicina de Ribeirão Preto;

— responder às perguntas feitas pelas famílias .

3. ${ }^{a}$ visita: para o Bairro $A$

- entrega dos resultados dos exames;

- prescrição para o tratamento;

- entrega dos medicamentos;

- orientação sobre os medicamentos;

- educação sanitária.

3. ${ }^{\mathrm{a}}$ visita: - para o Bairro $B$

- entrega dos resultados de exames;

- encaminhamento para o Centro de Saúde para o tratamento;

- educação sanitária.

Os pacientes deste grupo seriam encaminhados para aquisição de medicamentos porque:

— é difícil conseguir todo o medicamento necessário;

- por residirem na zona urbana, têm mais facilidade de acesso à Unidade de Saúde;

- é uma forma de ensiná-los a usar um recurso da comunidade. 
A colheita de dados será através de um questionário (anexo 1) discutido e aceito pelo grupo. Foram estabelecidas, também em classe, como deveria ser formulada cada pergunta e o cuidado para não induzir respostas.

\section{RESULTADOS}

Após colheita, tabulação e estudo dos dados obtidos, tivemos as seguintes informações:

$\mathrm{Na}$ cidade, as casas variavam de quatro a sete cômodos, todas elas de chão taqueado, tendo uma janela para cada cômodo, enquanto na periferia o número de cômodos foi de um a cinco, com piso de chão batido e outra cimentada, havendo casa com quatro ou cinco janelas e casa sem nenhuma janela.

\section{Agua}

Todas as casas da zona urbana possuíam água corrente dentro de casa, ligação esta da rede de abastecimento público. Na periferia somente uma casa possuía torneira com água vinda da rede pública, as outras famílias eram abastecidas por poço raso (uma) e as outras pelos caminhões dágua da Prefeitura local (duas).

\section{Destino dos Dejetos, Aguas Servidas e Lixo}

Na zona urbana todas as casas possuíam instalações sanitárias dentro de casa, possuindo ligações do sistema público de esgoto, e o lixo coletado diariamente pelo Serviço de Limpeza Pública. Na zona periférica as instalações eram fora das casas, havendo somente uma que possuía uma instalação dentro de casa e os dejetos eram encaminhados a um poço negro, enquanto duas usavam fossa seca e outra onde os dejetos eram depositados na superfície do solo. Quanto ao lixo, uma usava restos alimentares para alimentar os porcos e os demais deixavam no próprio terreno.

\section{Hortas e Criação de Animais}

Não foi encontrada horta na zona urbana, e numa casa havia galinhas, para o consumo da própria família. Não foi encontrada horta e criação de animais na periferia.

\section{Fixação na Localidade}

A residência anterior das famílias da cidade era em outros oairros da própria cidade e o tempo de residência nesse local 
variava entre o período de $0-1$ ano até de $20-40$ anos. Das 4 famílias residentes na periferia duas tinham vindo de outras cidades, uma veio da zona rural de outro Estado e uma veio de outro bairro da cidade, sendo que a fixação no local, quanto ao tempo, variava de 1 até 20 anos.

\section{Religião e Liderança}

Das oito famílias visitadas, sete declararam ser católicas e uma família declarou-se espírita.

No aparecimento de líder, só uma família da periferia fez indicação, as demais não o fizeram.

Providências em Caso de Doenças e Recursos de Assistência Médica

As quatro famílias da cidade providenciam médico, sendo que uma procura o Hospital das Clínicas ou Santa Casa e as outras três buscam médicos particulares.

$\mathrm{Na}$ periferia uma família usa remédio caseiro e as outras médico. O recurso médico, quando necessário, é o INPS, Santa Casa, Pronto-Socorro, Hospital das Clínicas e Posto de Saúde. mensal.

Idade, sexo, escolaridade, ocupação, caixa ou instituto e renda

Há uma correspondência entre a distribuição de número (quantidade) e sexo nas famílias da periferia e da cidade. A diferença é quanto à idade, pois na periferia há predominância para as idades de 0 a 10 anos (mais crianças) e na cidade de 10 a 80 anos (mais adultos) .

Quanto à escolaridade, na cidade não apareceram analfabetos e as ocupações variavam entre estudantes, comerciário, operário, dentista, professora, balconista, confeiteiro, prendas domésticas.

$\mathrm{Na}$ periferia as ocupações eram: domésticas, operários, pedreiro, jardineiro, prendas domésticas, sorveteiro e balconista. Foram encontrados seis pessoas analfabetas nesse grupo.

Tanto para periferia como para zona urbana, $50 \%$ deles são segurados pelo INPS. A renda-familar mensal na cidade variava de $\operatorname{Cr} \$ 500,00$ até $\operatorname{Cr} \$ 2.000,00$, sendo que não declinaram com exatidão o quanto recebiam mensalmente. 500,00 .

$\mathrm{Na}$ periferia, a renda-familiar variou entre $\operatorname{Cr} \$ 50,00$ até $\operatorname{Cr} \$ .$.

De uma forma geral houve dificuldade na obtenção desse dado (renda-familiar) pois na periferia devido o tipo de ocupação 
as rendas oscilam muito e em ambos os locais há uma certa insegurança em seu fornecimento.

\section{Observação Sobre os Quintais}

Os quintais da zona urbana cram todos calçados, limpos, arrumados ensolarados e bem ventilados. Em uma casa havia também canteiros ajardinados, enquanto na periferia todos os quintais eram de chão batido, à exceção de um que tinha um pedaço cimentado. Um foi considerado " "limpo" e os demais ** "mal cuidados". Eram bem ventilados e recebiam sol.

\section{Resultados dos Exames de Fezes}

Das 63 latas distribuídas, somente 41 foram devolvidas, sendo que menor devolução foi na zona urbana, que devolveu $46,8 \%$ enquanto a periferia devolveu $83,8 \%$.

A infestação maior foi o da periferia, atingindo mais o grupo de crianças, num total de positividade de $84,61 \%$. Na cidade os mais infectados foram os adultos, num total de $60 \%$ de positivos.

E de se notar que foram examinadas 41 pessoas, e o total de parasitados foi de 65 , isto por que muitos exames revelaram a presença de mais de um parasita.

Quanto à patogenicidade destes parasitas os resultados foram:

Na periferia houve predominância do áscaris lumbricóides e ancilóstomo, num total de $20,3 \%$, seguido pelo strongyloide com $15,0 \%$, endamoeba hystolítica $12,5 \%$ giardia lambia, $9,3 \%$, tricocefalus trichiura $1,7 \%$.

Na cidade houve predominância da endamoeba hystolítica $16 \%$, giardia lâmbia $16 \%$, tricocefalus $12 \%$, ancilóstomo $8,0 \%$ e enterobius vermicularis $4 \%$.

Do grupo dos não patogênicos, houve predominância na cidacle, onde o Endolimax nana apresentou $24 \%$, a endamoeba coli$10 \%$ e depois isosporo-hominis e iodamoeba bütschii com $4 \%$ cada.

$\mathrm{Na}$ periferia apareceram, a endamoeba coli com $10,9 \%$ e Endolimax nani $9,3 \%$.

\footnotetext{
(*) Limpo: - não havia lixo espalhado, havia ordeni nos objetos e era feita varredura.

$\left({ }^{\star *}\right)$ Mal Cuidados: - acúmulo de lixo, desordem nos objetos, ausência de varredura.
} 
O exame de laboratório que foi feito, não foi um bom exame para todos os tipos de parasitos, portanto, a força desse instrumento usado sof re restrições.

O método usado pelo laboratório foi o de Faust e sedimentação, o que permitiu o aparecimento de apenas um caso de oxiuríase e nenhum de teníase o que não significa ausência real desses vermes (o método usado é bom para áscaris e tricocéfalo) .

Embora tenham sido encontrados parasitas patogênicos e não patogênicos, todos eles levam a evidência da contaminação por excretas, isto é, a poluição do solo pelas fezes, principalmente no caso do áscaris em que as crianças se mostraram as mais atingidas, e são as que espalham as verminoses pelos quintais e mesmo dentro das casas.

O ancilóstomo e o Strongylóide descrevem um ciclo epidemiológico semelhante com penetração ativa através da pele, portanto o mesmo mecanismo de infestação que é permitido e mantido pelo solo contaminado, agravado pélo não uso de calçados.

De uma forma geral, todos eles estão ligados às condições de higiene pessoal, pelo solo contaminado por fezes, a falta de água ' $m$ quantidade e qualidade para as necessidades da família, os alimentos desprotegidos facilitando o acesso de moscas e baratas que pululam nos lixos espalhados e amontoados nos quintais e ainda os possíveis portadores sãos no caso da Endamoeba hystolítica, dos que manipulam alimentos.

$\mathrm{Na}$ cidade, o aparecimento de verminoses deveu-se a uma família, que fomos rever e obter mais informes, pois era constituída por 13 pessoas, o casal e onze filhos e quase todos parasitados, residinclo num bairro com todas as condições favoráveis para não se ter verminose, uma vez que a melhoria da urbanização e da habitação tem modificado as condições do solo.

$O$ que obtivemos é que realmente a família tinha vindo de urn bairro da cidade, mas aí esteve por um tempo curto, enquanto aguardava essa casa. Tinha chegado recentemente de uma cidade interiorana de um Estado vizinho, dum local com mínimos recursos de saneamento e ainda não havia feito nenhum exame médico ou tratamento aqui (no Estado de São Paulo).

\section{CONCLUSÃO}

No relatório final os alunos mostraram:

— evidências de aparecimento de verminoses e condições do meio ambiente;

—necessidade de intensifcar educação em saúde e saneamento básico, principalmente na periferia da cidade; 
- importância do trabalho conjunto da própria população e os poderes públicos para implantação de melhorias;

- que o trabalho agradou, por entrarem em contato com situações que ainda não conheciam e pela oportunidade de aplicarem conhecimentos que foram adquiridos em outras disciplinas como: Parasitologia, Sociologia, Estatística e Relações Humanas.

Quanto a nós que demos o curso, que acompanhamos os alunos em todas as fases do trabalho, achamos que foi uma experiência compensadora. Permitiu que os alunos tomassem conhecimento dos problemas que existem entre o homem e seu meio. Isto proporciona ao profissional, conhecimentos para planejar e programar ações que tragam melhoria de condições e promoções de saúde.

Foi um trabalho que trouxe sobrecarga de horas e exigiu do professor uma supervisão constante em todas as fases, por tratar-se de alunos do primeiro ano. Houve dificuldades que são inerentes a trabalho de campo (locomoção, material, número grande de alunos), mas mesmo assim o trabalho foi agradável, contando com a participação entusiástica do grupo.

Duas objeções poderiam ser feitas ao trabalho: ser muito exaustivo e a metodologia não obedecer as exigências de amostragem. Apesar dessas objjeções, julgamos ter sido uma experiência positiva pela oportunidade que tiveram os futuros enfermeiros de conhecerem problemas de saneamento existentes em nossa comunidade, e das oportunidades de trabalho, que tem o profissional de saúde, junto a esses grupos.

Achamos que nossos objetivos foram alcançados, como mostram as conclusões apresentadas pelos próprios alunos.

Apesar do trabalho ter sidó exaustivo, não obedecendo à exigências de amostragem, julgamos ter sido uma experiência positiva pelas oportunidades que ele ofereceu ao aluno para trabalhar na comunidade.

\section{REFERENCIA BIBLIOGRÁFICA}

1 - PESSOA, Samuel Barnsley Parasitologia Médica. 17.* ed. Rio de Janeiro, Editora Guanabara Koogan, 1969.

2 - NEGHME, Amador; SILVA, Roberto. Ecologia del parasitismo en el hombre. Boletim de la Oficina Sanitaria Panamericana, 70 (4):313:329, Abr. 1971.

3 - ORGANIZAÇÃO MUNDIAL DA SAƯDE. Comité D'Experts de L'Assainissement. Rapport sur la première session Genëve, Mai., 1950 (Serie de Inf. Tec. n.9 10). 


\section{BIBLIOGRAFIA CONSULTADA}

1 - ALVIN, Emengarda de Faria. La preparacion de enfermeras de salud publica en el Brasil Boletin de la Oficina Sanitaria Panamericana 55 (4):433-439, Oct. 1963.

2 - BEAL, G.M.; BOHLEN, J.M.; - RAUDABAUGH, J.N. Lidederança e Dinâmica de Grupo. Trad. de Waldir da Costa Godolphim e Sigrid Faulhaber-Godolphim. 2." ed. Rio de Janeiro, Zahar editores, 1965.

3 - LEAHY, Kathleen, M.; COBB, Marguerite, M. Enfermeria $e$ Salud Publica. México, Editorial Interamericana, 1968.

4 - MANCEAU, J.N.; ALBUQUERQUE, Anibal M.; MAROJA, Rainero. Diarréia infantil e condições sanitárias do meio-ambiente. Boletin de la Oficina Sanitaria Panamericana, 49(3): 244-252. Sep. 1960.

5 - ORGANIZAÇÃO MUNDIAL DA SAƯdE. Expert Comettee on Environmental Sanitation. Second report. Geneva, 1952 (Technical report series n.9 47).

5 - ORGANIZAÇÃO MUNDIAL DA SAÚDE. Expert Comittee on Environmental Sanitation. Third report. Geneva. Abr. 1954 (Technical report series n.9 77).

7 - ORGANIZAÇÃO MUNDIAL DA SAƯDE. Helmintos transmitidos por el solo. Informe de um Comitê de Expertos de 1.* O.M.S. em Helmintiasis. (Série de Inf. Téc. n.9 277).

8 - Seminário Sobre Diarréias Infantis. Recife, Pernambuco, 16 a 21 de novembro de 1959. Relatório final. Boletin de la Oficina Sanitaria Panamericana, 49(3): 253-263. Sept. 1960.

9 - WAGNER, E.G.; LANDIX, J.N. Saneamento básico. Traduzido e adaptado da monografia n.9 39. Evacuación de excretas en las zonas rurales y en las pequenas comunidades. Rio de Janeiro, M.S. - DNERu, 1964. 